\title{
Heating and emission characteristics of briquettes developed from spent coffee grounds
}

\author{
Yeongsu Kim ${ }^{1}$, Tusan Park ${ }^{1,3}$, Donghyuck Hong ${ }^{1,2^{+}}$ \\ ${ }^{1}$ Department of Bio-industrial Machinery Engineering, Kyungpook National University, Korea \\ ${ }^{2}$ Upland-Field Machinery Research Center, Kyungpook National University, Korea \\ ${ }^{3}$ Smart Agriculture Innovation Center, Kyungpook National University, Daegu 41566, Korea
}

\begin{abstract}
The development of biomass fuels to replace fossil fuels is on the rise, with increased bioenergy research on spent coffee grounds (SCG). However, no biofuel can currently replace anthracite briquettes. Unlike ordinary solid fossil fuels, anthracite briquettes are heated for a long time and retain the same form after combustion, making them easier to transport. In this study, binders are used to develop a solid fuel that allows SCG to retain their shape after combustion. Specifically, bottom ash (BA) and kaolinite clay (KC) are mixed in different ratios then processed with a press machine and cured to produce briquettes that exhibit zero damage, even after combustion. The results show that the optimal composition for SGC briquette production according to fuel quality and ash shape retention is $20 \mathrm{wt}$ \% SCG; $71 \mathrm{wt} \%$ BA; 9 wt.\% KC; and 15 wt.\% solution with a $20: 1$ water $/ \mathrm{Ca}(\mathrm{OH})_{2}$ mixing ratio. This results in a low heating value of $15.8 \mathrm{MJ} / \mathrm{kg}, 86.82 \%$ durability before combustion, and $99.46 \%$ durability after combustion. In addition, combustion tests with SCG briquettes confirmed their potential as an environmentally friendly alternative fuel to anthracite briquettes.
\end{abstract}

Keywords: Anthracite, Binder, Bottom ash, Briquette, Kaolinite clay, Spent coffee grounds

\section{Introduction}

Coal combustion emits harmful gases such as $\mathrm{NO}_{2}, \mathrm{SO}_{2}, \mathrm{CO}_{2}$, and CO [1]. While efforts have been made to reduce the emission of harmful gases during industrial coal consumption, the coefficient of pollutant emissions produced by burning household coal may be 100 times higher than that produced by power plant coal boilers [2]. Moreover, it is expected that the demand for anthracite briquettes will continue for decades due to their low unit cost and ease of use in greenhouse complexes and rural areas [3, 4]. However, anthracite briquettes are frequently linked to carbon monoxide poisoning due to the high $\mathrm{CO}$ concentration in the combustion engine [1]. To solve these problems, it is necessary to find renewable sources of energy that can replace fossil fuels. Among them, spent coffee grounds (SCG) have been the subject of various studies into types of biodiesel and pellets, which have indicated their potential as biofuel [5-8].

In 2021, coffee consumed about 9.99 million tons worldwide and is the second most consumed product after petroleum [9].
A ton of coffee beans created about $650 \mathrm{~kg}$ of SCG [10-12] and 6.49 million tons of SCG are created in 2021. Large-capacity of SCGs that were occurred every day around the world are low in market value, lack of effective treatment methods and landfill disposal, the current major treatment method, is causing many environmental problems [13, 14].

To use SCG as a solid fuel, problems related to their high moisture content, irregular particle size and shape, and low density must first be solved as these problems affect handling, transportation, storage, and utilization [15-17]. Binders can be used to improve drying, carbonation, grinding, particle linespecific operations, adhesion, and compressive strength [18-20]. In addition, SCG do not form ash after combustion because of their low ash content, making it difficult to replace the briquettes when used as an alternative fuel for anthracite briquettes. In order to utilize SCG as a renewable alternative fuel to anthracite briquettes, the quality standards of anthracite briquettes (Ministry of Trade, Industry and Energy No. 17) and Bio-SRF (Ministry of Environment Examination No. 20) must be satisfied, which requires the use of binders to
This is an Open Access article distributed under the terms of the Creative Commons Attribution Non-Commercial License (http://creativecommons.org/licenses/by-nc/3.0/) which permits unrestricted non-commercial use, distribution, and reproduction in any medium, provided the original work is properly cited.

Copyright (C) 2022 Korean Society of Environmental Engineers
Received February 01, 2021 Accepted May 30, 2021

${ }^{\dagger}$ Corresponding author

E-mail: bear0011@knu.co.kr

Tel: +82 539505790 Fax: +82 539506780

ORCID: 0000-0002-9411-541X 
manufacture heat generation characteristics similar to those of anthracite briquettes [21, 22].

Coal ash is generated during coal-fired power generation, with $80 \%$ of fly ash (FA) and $20 \%$ bottom ash (BA) [23, 24]. Among them, BA contains unburned carbon (non-burned carbon) and is not suitable for recycling because of problems such as turning the concrete black or reduced strength when used as a construction material [25]. However, BA contains more calories than FA, which could enable solid fuel utilization. In addition, the $\mathrm{SiO}_{2}+\mathrm{Al}_{2} \mathrm{O}_{3}+\mathrm{Fe}_{2} \mathrm{O}_{3}$ in BA contains approximately 80 wt.\% of pozolane, which can be cured at temperatures of $20-85^{\circ} \mathrm{C}$, confirming the possibility of recycling BA as a material for SCG briquette manufacturing [26-28].

Kaolinite clay $(\mathrm{KC})$ is a clay material widely used for many purposes, such as ceramics, paper coating, paper filling, paint extenders, rubber filler, plastic fillers, cracking catalysts, and contracts [29, 30]. KC exhibits adhesion in response to water and can be used to maintain the shape of briquettes after combustion owing to its properties of curing and turning white at high temperatures [31].

Recently, many studies have analyzed SCG characteristics for energy use in boiler systems [32, 33] and the use of binders to increase SCG durability [34]. Kang et al. [35] investigated SCG combustion characteristics in a small boiler system $(6.5 \mathrm{~kW}$ based on the input low heating value (LHV)). A higher nitrogen content in the SCG led to higher NOx emissions during combustion compared to wood pellets, which requires a more precise boiler design to ensure adequate efficiency and emission performance [35]. Moreover, Law et al. [36] selected rice husk, sugarcane bagasse, and SCG as raw materials for manufacturing briquettes. The mechanical properties of the briquettes were measured in terms of their shatter retention, abrasive retention, water retention, etc., and were found to be effectively improved from that of pure SCG by the inclusion of rice husk and sugarcane bagasse. Espuelas et al. [18] analyzed the availability of SCG used in briquette production with xanthan and guar as binders. The binders reduced volatile matter, increased the fixed carbon content, and reduced the nitrogen content. However, there have been no attempts to manufacture briquettes using SCG as a replacement for anthracite, and no studies have been conducted on the use and characteristics of binders that can replicate the properties of anthracite.

Therefore, the biomass briquettes with coffee as the main ingredient in an attempt to find a suitable replacement for existing anthracite briquettes were manufactured in this study. Evaluate the potential of the SCG as an alternative fuel and determine optimal manufacturing conditions.

\section{Materials and Methods}

\subsection{Materials}

SCG were dried for $24 \mathrm{~h}$ at $105^{\circ} \mathrm{C}$ in a dry oven, then immediately heated and carbonized for $50 \mathrm{~min}$ at $290^{\circ} \mathrm{C}$ in a stirrup roaster. $\mathrm{BA}$ and $\mathrm{KC}$ were transported to JAEIL (JAE-IL INSTREMENT COMPANY, Korea) and dried for $24 \mathrm{~h}$ at $55^{\circ} \mathrm{C}$ in a dry oven. Samples were stored in a sealed container until the next step.

\subsection{Conditions for SCG Briquette Production}

Crushed carbonated SCG, BA, and KC, and scoured particles smaller than $175 \mu \mathrm{m}$ (after mesh screening) were mixed in five different ratios, as shown in Table S1, so that the weight of each specimen was $10 \mathrm{~kg}$. A water and $\mathrm{Ca}(\mathrm{OH})_{2}$ solution in a ratio of 20:1 was added to each mixture to represent 15 wt.\% [37-39]. The solution was added and mixed for $10 \mathrm{~min}$. Each specimen was molded without heating at a compression pressure of $20 \mathrm{MPa}$ to a shape $150 \mathrm{~mm}$ in diameter and $142 \mathrm{~mm}$ in height with 22 air holes ( $\mathrm{D}=14 \mathrm{~mm}$ ) using a briquette molding presser typically used to mold anthracite into briquettes [40].

\subsection{Briquette Combustion}

Combustion tests of SCG briquettes and anthracite briquettes were conducted simultaneously with ignition coals which have $20 \mathrm{~min}$ combustion time, through a boiler (TH 180, TAEHYUNG INDUSTRY CO., LTD, Korea). For each test, one SCG briquette and one Anthracite briquette were burned in the boiler. At this time, the ambient air temperature was $10-12^{\circ} \mathrm{C}$ and the oxygen saturation concentration was $13 \%$. Each briquette was burned until it could be heated no longer.

\subsection{Analysis of SCG Briquettes}

The briquettes should maintain their shape after molding and should have sufficient durability for transport. In addition, because it is a solid fuel that can be used in domestic or horticultural briquette boilers, the ash should be cured after combustion and maintained in its original form, enabling post-treatment for briquette removal. The briquettes in this study are formed by mixing BA and $\mathrm{KC}$ in a carbonated SCG mixing ratio of $20-70 \%$. Measurements of SCG briquette durability, LHV, heating time, $\mathrm{CO}, \mathrm{CO}_{2}, \mathrm{NO}_{2}$, and $\mathrm{SO}_{2}$ are then compared with those for anthracite briquettes to evaluate the potential of SCG as an alternative fuel and determine the optimal manufacturing conditions. The physical and chemical characteristics of the manufactured SCG briquettes, such as volatile matter, ash content, and sulfur content, are also analyzed.

The compressive force was measured for hardness analysis before and after combustion of the five different SCG briquettes and anthracite briquettes. The center of the outer diameter was measured by laying the cylinder shaped bracket flat, and the spherical probe (D $=8 \mathrm{~mm}$ ) of the ultrasonic thickness measurement device (LTCM-100, Ametek, USA) was lowered at a speed of $35 \mathrm{~mm} / \mathrm{s}$ to measure three samples for each bracket.

To measure the combustion time of SCG briquettes and anthracite briquettes, the temperature of the briquettes burned in briquette boilers was measured using a thermal imaging camera (Fluke Ti 105, Fluke, USA). The combustion time was measured as the time from the point of ignition to the time when the briquette temperature dropped below $800^{\circ} \mathrm{C}$.

Combustion gas generated two hours after ignition of the briquette samples was collected in a multilayer $10 \mathrm{~L}$ foil bag (Foil Bag 10, SANT Nano Technology, Korea) using a gas collector (Gas Collector 10, SANT Nano Technology, Rep. Korea). The amounts of CO, $\mathrm{H}_{2} \mathrm{~S}, \mathrm{CO}_{2}, \mathrm{SO}_{2}$, and $\mathrm{NO}_{2}$ contained in the collected gas were measured by a $\mathrm{CO}$ and $\mathrm{H}_{2} \mathrm{~S}$ meter (VENTIS MX4, Industrial Scientific, USA), a $\mathrm{CO}_{2}$ meter (IAQ-CALCTM, TSI, USA), an $\mathrm{SO}_{2}$ meter (MINIMAX 
XP-SO ${ }_{2}$, Honeywell, USAX), and an $\mathrm{NO}_{2}$ meter (MINIMAX XP-NO Honeywell, USA), respectively.

The properties of the briquettes before combustion and the water content, LHV, carbon content, sulfur content, and ash content generated after combustion were analyzed according to analysis standards [21, 22].

\section{Results and Discussion}

\subsection{Durability of the SCG Briquettes}

Compared to the average compressive strength of briquettes made of anthracite $(570 \mathrm{~N})$, the average compressive power of the briquettes containing 20-50 wt.\% SCG was 14\% lower at $488-494$ $\mathrm{N}$, whereas that of briquettes containing 60-70 wt.\% SCG was 50.8\% lower at $280 \mathrm{~N}$ (Fig. 1). Analysis of the compressive strength of briquettes after combustion showed an average compressive force of $46 \mathrm{~N}, 45 \mathrm{~N}$, and $22-25 \mathrm{~N}$ for briquettes made of anthracite, 20-30 wt.\% SCG, and 50 wt.\% SCG, respectively (Fig. 1).

One-way distribution analysis of the measured compression force according to SCG content showed the highest value for anthracite briquettes before combustion, followed by 20 wt.\% SCG, 30 wt.\% SCG, and 50 wt.\% SCG briquettes, then 60 wt.\% SCG and 70 wt.\% SCG briquettes. The F value was 589.343 and the $\mathrm{P}$ value was 0.000 , indicating a significant difference in briquette durability due to SCG content. The average post-combustion force values were similar for anthracite, 20 wt.\% SCG, and 30 wt.\% SCG briquettes, which were double those of 60 wt.\% SCG briquettes and 70 wt.\% SCG briquettes. However, the range of average error in the measurement of the compression force of post-combustion ash was large, resulting in all briquettes falling in the same group (except for 70 wt.\% SCG briquettes). The value of F was 3.307, and the value of $\mathrm{P}$ was 0.042 , indicating that the variation in briquette durability with SCG content was significant.

Biomass is characterized by a large amount of volatile matter, low ash, low density, and a low heating value [41]. The hydrocarbon

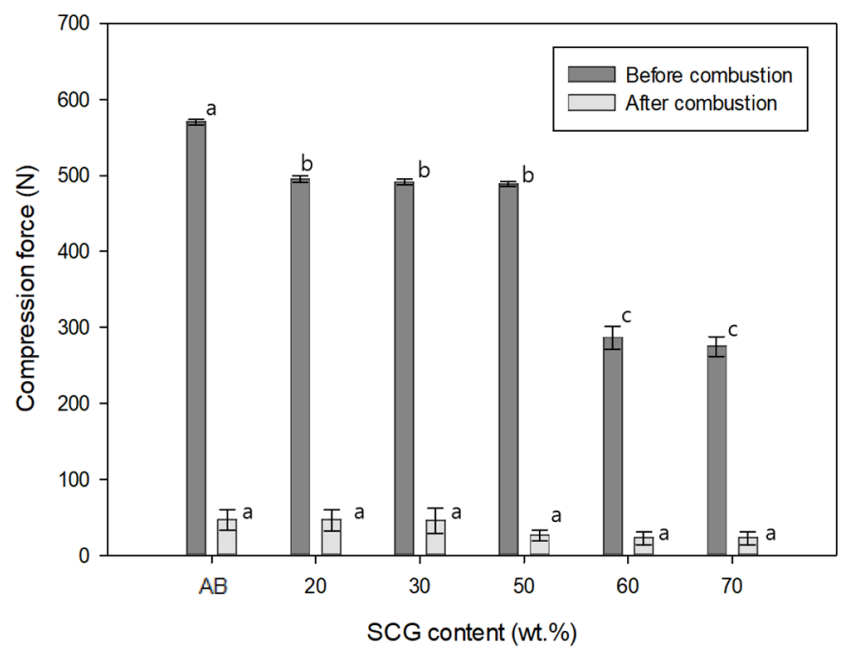

Fig. 1. Durability of anthracite briquettes (AB) and SCG briquettes before and after combustion. process could improve the high heating value by up to $38 \%$ [42]. Tsai and Liu [43] found that the maximum true density of SCG was approximately $1.332 \mathrm{~g} / \mathrm{cm}^{3}$, with the carbonation temperature decreasing to approximately $289.85^{\circ} \mathrm{C}(563 \mathrm{~K})$. This is due to the process of releasing gasoline from the SCG hole, which results in an increase in density of up to $1.274 \mathrm{~g} / \mathrm{cm}^{3}$, which can increase the density of the SCG if sufficient carbonation is achieved.

The selected $\mathrm{BA}$ and $\mathrm{KC}$ materials contained $80 \%$ $\mathrm{SiO}_{2}+\mathrm{Al}_{2} \mathrm{O}_{3}+\mathrm{Fe}_{2} \mathrm{O}_{3}$ because adhesion is important when water or hardening agents are added. The $\mathrm{BA}$ composed of $\mathrm{SiO}_{2}$ and $\mathrm{Al}_{2} \mathrm{O}_{3}$ was cured using water and $\mathrm{Ca}(\mathrm{OH})_{2}$ [44-46]. In addition, $\mathrm{KC}$, which exhibits adhesion in response to water and becomes hard and white at high temperatures, allows the formation of ash after combustion [31].

The SCG briquettes exhibited reduced compressive strength as the ratio of SCG increased because the particles in SCG are less dense than those in BA, KC, and anthracite (Fig. 1). Low particle density appears to increase the pore rate between particles during the compression process and reduce density, thereby reducing the durability and compressive strength [47]. When burning briquettes were removed from the stove with briquette tongs, the anthracite, 20 wt.\% SCG, and 30 wt.\% SCG briquettes were not broken; however, those with SCG contents greater than 50 wt.\% were broken. Post-combustion compressive force data of the SCG briquettes suggest that those with an SCG content of $50 \%$ or more are inadequate for use as briquettes because they are not sufficiently durable (Fig. 1). For pre-combustion 50 wt.\% SCG samples, there was minimal difference in compression strength from the 20-30 wt.\% SCG samples; however, the post-combustion compressive strength of 50 wt.\% SCG samples was similar to that of $60-70$ wt.\% SCG samples.

\subsection{Physicochemical Properties of the SCG Briquettes}

In order to actually use a briquette made with biomass, appropriate physical and chemical standards must be met. Table 1 presents an analysis of the physical and chemical characteristics of SCG briquettes according to SCG content. The sulfur content and water content of SCG briquettes satisfied both the Quality of Trade (Ministry of Trade, Industry and Energy No. 17) and Solid Refuse Fuel (SRF) quality standards (Minister of Environment Examination No. 20).

Volatile matter was below $7.0 \%$ quality standard of anthracite briquettes because coal with high $\mathrm{N}$ and $\mathrm{S}$ is oxidized, resulting in harmful $\mathrm{NO}_{2}$ and $\mathrm{SO}_{2}$ emissions. However, the combustion of SCG mixed with coal fuel results in not only low nitrogen content biomass material but also an effective method of reducing $\mathrm{NO}_{\mathrm{x}}$ emissions due to the synergistic effects on combustion, which requires usability verification through harmful gas testing of more than $7.0 \%$ of the volume matter [48]. The ash content was higher than the SRF quality standard; therefore, it did not satisfy the quality standard. However, the higher the ash content, the more stable the shape of the briquette. Moreover, it is desirable to follow anthracite briquette specifications because the SCG briquette is an existing briquette boiler that uses anthracite briquettes as fuel. In the case of LHV, the anthracite briquette quality standard was not satisfied except for briquettes with an SCG content of 70 wt.\%. 
Table 1. Physicochemical Properties of SCG Briquettes Compared with Briquette and SRF Quality Standards

\begin{tabular}{|c|c|c|c|c|c|c|c|c|}
\hline \multirow{2}{*}{ Specification } & \multirow{2}{*}{ Unit } & \multirow{2}{*}{ AB quality standard } & \multirow{2}{*}{ SRF quality standard } & \multicolumn{5}{|c|}{ SCG briquette (wt.\%) } \\
\hline & & & & 20 & 30 & 50 & 60 & 70 \\
\hline Volatile matter & $\%$ & $<7.0$ & - & 10.2 & 10.8 & 11.5 & 17.9 & 16.7 \\
\hline Water content & wt.\% & - & $\leq 10$ & 1.2 & 1.2 & 1.4 & 1.6 & 1.6 \\
\hline Ash content & wt.\% & - & $\leq 20$ & 47.5 & 46.1 & 44.2 & 40.5 & 32.4 \\
\hline Lower heating value & $\mathrm{MJ} / \mathrm{kg}$ & 18.4 & 14.6 & 15.8 & 15.7 & 16.8 & 17.1 & 19.7 \\
\hline Sulfur content & wt.\% & $<1.0$ & $\leq 0.6$ & 0.22 & 0.19 & 0.14 & 0.07 & 0.05 \\
\hline
\end{tabular}

However, the SRF quality standard was satisfied; therefore, the developed briquettes have value as a solid fuel.

\subsection{Combustion Characteristics of the SCG Briquettes}

Fig. 2 shows the LHV according to SCG content for anthracite and SCG briquettes. The LHV of anthracite briquettes was $18.4 \mathrm{MJ} / \mathrm{kg}$, whereas that of SCG briquettes increased with increasing SCG content. An increase in the ratio of SCG, which has a high calorific value of $28.4 \mathrm{MJ} / \mathrm{Kg}$, also increased the calorific value of the SCG briquette. If necessary, the calorific value can be adjusted by varying the SCG content. The LHVs of briquettes with 20 wt.\% SCG and 30 wt.\% SCG were similar at $15.8 \mathrm{MJ} / \mathrm{kg}$. The briquette with 70 wt.\% SCG had the highest LHV of $19.7 \mathrm{MJ} / \mathrm{kg}$, followed by that with 60 wt.\% SCG (17.1 MJ/kg) and 50 wt.\% SCG (16.8 MJ/kg).

According to a biomass boiler operation experiment conducted by Fournel et al. [54], the LHVs of pelletized biomass solid fuels such as wood, short-rotation willow, switchgrass, miscanthus, and reed canary grass are 14.3-16.3 M/ $/ \mathrm{kg}$, with an average of $15.2 \mathrm{MJ} / \mathrm{kg}$. Among the SCG briquettes, the briquette with 20 wt.\% SCG had the lowest LHV of $15.8 \mathrm{MJ} / \mathrm{kg}$; however, this was still higher than the average LHV of a typical biomass fuel, which is $15.2 \mathrm{MJ} / \mathrm{kg}$.

Fig. 3 shows the duration of heat generation for the briquettes according to SCG content for anthracite and SCG briquettes. Anthracite briquettes molded at $2.9 \mathrm{~kg}$ had the longest combustion time of $570 \mathrm{~min}$. Among SCG briquettes molded at $2.4 \mathrm{~kg}, 20$ wt.\% SCG briquettes exhibited the longest combustion time of $555 \mathrm{~min}$. As the content of SCG in the briquette increased, the

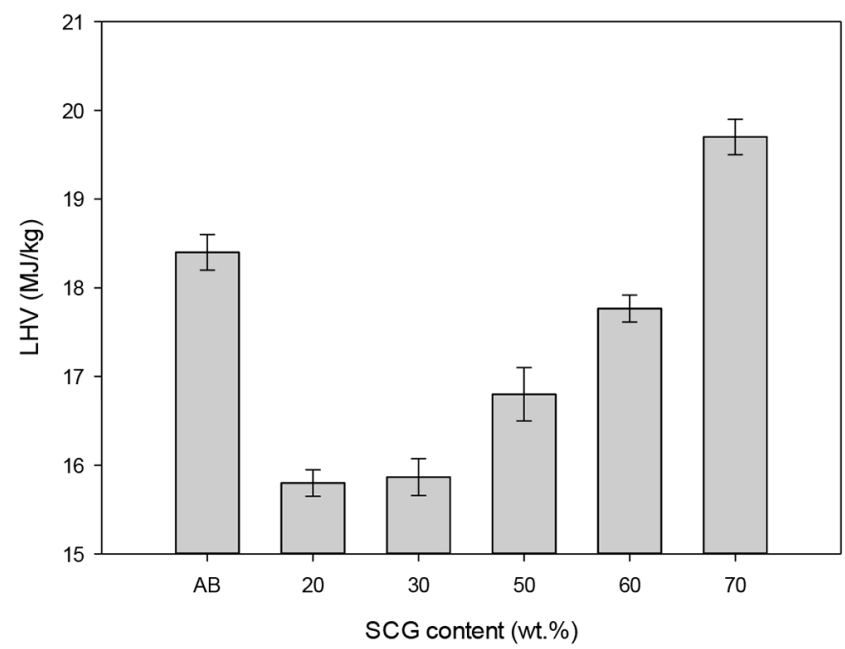

Fig. 2. LHV according to SCG content for anthracite and SCG briquettes.

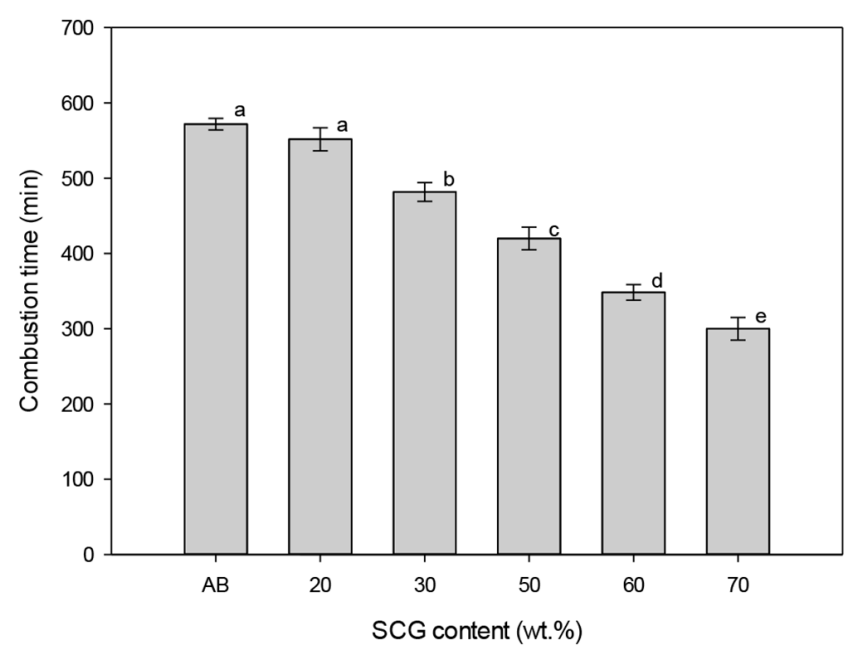

Fig. 3. Combustion time according to SCG content for anthracite and SCG briquettes.

combustion time tended to decrease. Anthracite briquettes and 20 wt.\% SCG briquettes belonged to group a, 30 wt.\% SCG briquettes belonged to group b, 50 wt.\% SCG briquettes belonged to group c, 60 wt.\% SCG briquettes belonged to group d, and 70 wt.\% SCG briquettes belonged to group e. The F value was 213.355 and the $P$ value was 0.000 , indicating a significant difference in combustion time according to SCG content.

According to a study by Kim et al. [50], when looking at the reaction characteristics of pulverized coal, BA, and FA using a drop tube furnace, no significant differences were observed among samples in terms of the conversion rate, activation frequency, or activation energy. Based on these results, it was determined that a mixing rate of approximately 10\% under the conditions of a short residence time and high heating rate (similar to an actual combustion state) did not significantly affect the combustion reactivity. The BA and FA from a thermal power plant could be used as mixed renewable fuels by mixing them with existing pulverized coal, and the co-consumption rate could be increased depending on the actual thermal power plant operating conditions and ash properties [50]. Therefore, the combustion stability of SCG briquettes is expected to increase with increasing BA content in the SCG briquette.

\subsection{Harmful gas Emission Analysis}

The air pollutant emission standards (Article 15 of the Enforcement Regulations of the Air Conservation Act, Ministry of Environment Decree No. 866, 2020), which were revised and effective from April 
2020 and apply to $\mathrm{CO}, \mathrm{CO}_{2}, \mathrm{NO}_{2}, \mathrm{SO}_{2}$, dust, etc., provide the criteria for general boilers, power generation facilities, manufacturing and refining facilities, waste, waste gas, and incineration facilities. With a general boiler, the CO emission limit is less than 50-300 ppm in solid fuel facilities, less than $300 \mathrm{ppm}$ for SRF, and less than 200 ppm for biomass. $\mathrm{NO}_{2}$ emissions are limited to less than 70-120 ppm, and $\mathrm{SO}_{2}$ emissions should be less than 70-180 ppm [51]. In order to meet these emission limits, various studies have been conducted on the combustion methods, treatment, and discharge of waste gases.

Fig. 4 and Fig. 5 show the concentrations of $\mathrm{CO}$ and $\mathrm{CO}_{2}$ measured by collecting the gas discharged during combustion of briquettes according to the SCG content. For anthracite briquettes, the CO and $\mathrm{CO}_{2}$ concentrations were $995 \mathrm{ppm}\left(13 \% \mathrm{O}_{2}\right)$ and 2,900 ppm $\left(13 \% \mathrm{O}_{2}\right)$, respectively. For SCG briquettes, the $\mathrm{CO}$ and $\mathrm{CO}_{2}$ concentrations were 8-48 ppm $\left(13 \% \mathrm{O}_{2}\right)$ and $929-2,180 \mathrm{ppm}\left(13 \% \mathrm{O}_{2}\right)$, respectively.

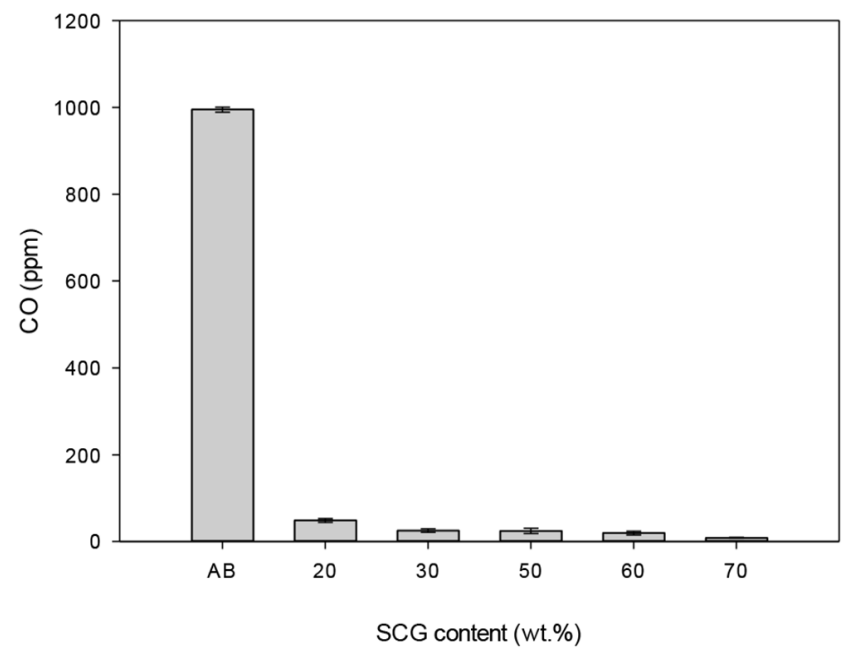

Fig. 4. $\mathrm{CO}$ concentration according to SCG content $\left(13 \% \mathrm{O}_{2}\right)$ for anthracite and SCG briquettes.

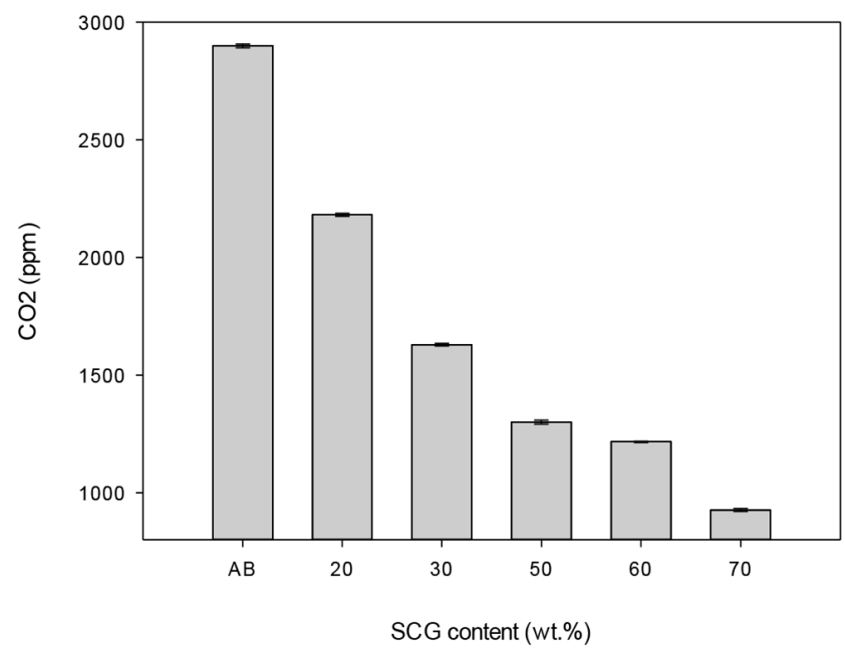

Fig. 5. $\mathrm{CO}_{2}$ concentration according to SCG content $\left(13 \% \mathrm{O}_{2}\right)$ for anthracite and SCG briquettes.
According to Obernberger et al. [52], incomplete combustion of briquettes leads to the release of unburned carbon-based pollutants such as carbon monoxide, hydrocarbons, polycyclic aromatic hydrocarbons, tar, and soot. Therefore, the lower concentrations of $\mathrm{CO}$ and $\mathrm{CO}_{2}$ from the SCG briquettes suggest that the SCG briquettes burn more completely than anthracite briquettes. In addition, even among SCG briquettes, a higher SCG content leads to fewer $\mathrm{CO}$ and $\mathrm{CO}_{2}$ gas emissions (Fig. 4 and Fig. 5).

In the case of SCG briquette, 46.1-54.9 wt.\% of carbon content, was measured to be less carbon content then anthracite briquette, 75.23 wt.\% of carbon content (Table S2), indicating less CO and $\mathrm{CO}_{2}$ were discharged from combustion [46, 53].

In general, biomass generates pollutants such as $\mathrm{NO}_{\mathrm{x}}, \mathrm{SO}_{\mathrm{x}}$, and particles during combustion because of fuel components including $\mathrm{N}, \mathrm{K}, \mathrm{Cl}, \mathrm{Ca}, \mathrm{Na}, \mathrm{Mg}, \mathrm{P}$, and S [54]. These pollutants not only directly irritate the human respiratory tract, causing inflammation and damage, but also indirectly trigger photochemical smog reactions. Considering the effects of $\mathrm{NO}_{\mathrm{x}}$ and $\mathrm{SO}_{\mathrm{x}}$ on the human body, $\mathrm{NO}_{2}$ causes more damage to the human body than $\mathrm{NO}$ [54-56].

Fig. 6 shows the concentration of $\mathrm{NO}_{2}$ generated during the combustion of anthracite and SCG briquettes according to SCG content. After combustion, the $\mathrm{NO}_{2}$ concentration in anthracite briquettes was as low as $2.2 \mathrm{ppm}\left(13 \% \mathrm{O}_{2}\right)$. Conversely, the $\mathrm{NO}_{2}$ concentration was 3.7 ppm for the briquette with 20 wt.\% SCG, which was higher than that generated by the anthracite briquettes. The $\mathrm{NO}_{2}$ concentration gradually decreased to $1.3,1.2,1.0$, and $0.7 \mathrm{ppm}$ for the briquettes with 30-70 wt.\% SCG, indicating a decrease in $\mathrm{NO}_{2}$ generation with increasing SCG content.

According to Nussbaumer [57], during the combustion process, the nitrogen fuel component is converted into $\mathrm{N}_{2}$ and $\mathrm{NO}_{\mathrm{x}}$, with very small amounts of $\mathrm{NO}_{2}$ present in the combustion gases generated from recent biomass solid fuels. The fuel $\mathrm{N}$ content is responsible for $\mathrm{NO}_{\mathrm{x}}$ formation (Table S2). The amount of $\mathrm{NO}_{2}$ emitted from the SCG briquettes used in this study was also low, demonstrating combustion characteristics similar to those of recent biomass solid fuels (Fig. 6). $\mathrm{NO}_{\mathrm{x}}$ is formed by the reaction of $\mathrm{N}$ in air at temperatures above $1,300^{\circ} \mathrm{C}$. As the temperature increases, the

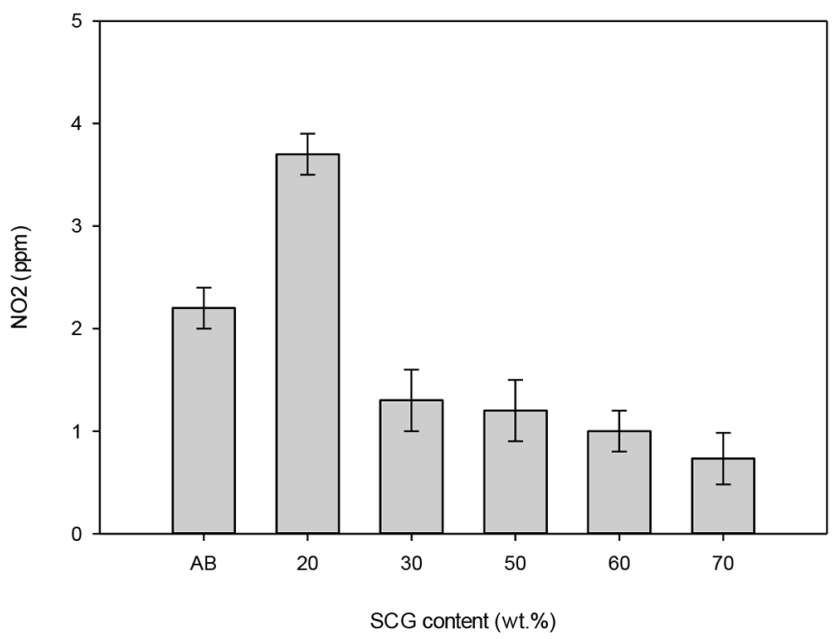

Fig. 6. $\mathrm{NO}_{2}$ concentration according to SCG content $\left(13 \% \mathrm{O}_{2}\right)$ for anthracite and SCG briquettes. 


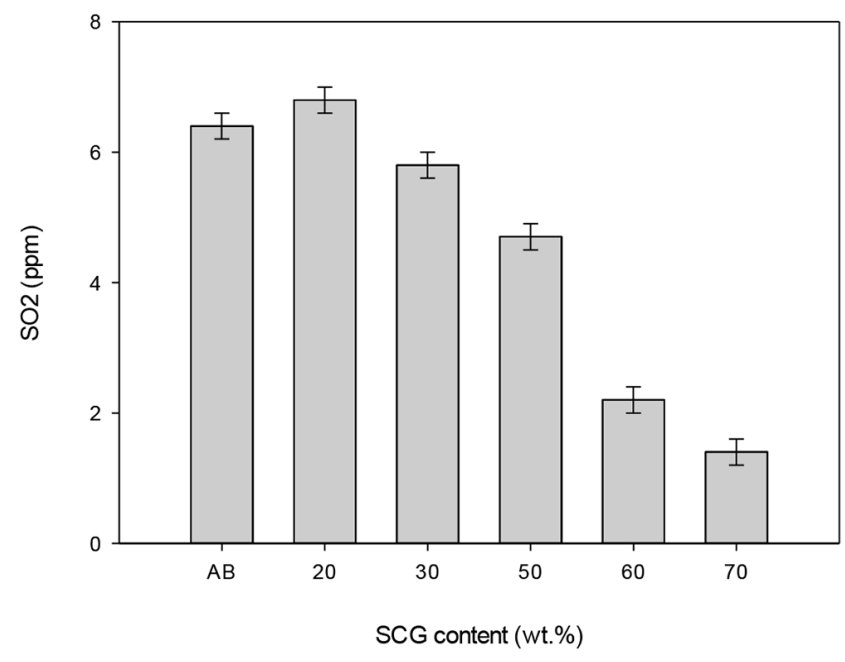

Fig. 7. $\mathrm{SO}_{2}$ concentration according to SCG content $\left(13 \% \mathrm{O}_{2}\right)$ for anthracite and SCG briquettes.

amount of $\mathrm{NO}_{\mathrm{x}}$ generation increases [52]. As biomass solid fuels such as SCG briquettes have a temperature of approximately $800-1,200^{\circ} \mathrm{C}$ during combustion, they tend to have a relatively low $\mathrm{NO}_{2}$ concentration.

Fig. 7 shows the concentration of $\mathrm{SO}_{2}$ generated during the combustion of anthracite and SCG briquettes according to SCG content. For anthracite briquettes, the amount of $\mathrm{SO}_{2}$ generated was as low as $6.4 \mathrm{ppm}\left(13 \% \mathrm{O}_{2}\right)$. This seems to be the result of anthracite briquette manufacturing regulations that keep volatile substances to less than 7.0 wt.\% and sulfur to less than 1.0 wt.\%. For 20 wt.\% SCG briquettes, the amount of $\mathrm{SO}_{2}$ generated was $6.8 \mathrm{ppm}\left(13 \% \mathrm{O}_{2}\right)$, which was higher than that of anthracite briquettes. This was because the sulfur content of the SCG briquettes exceeded the 7.0 wt.\% limit set by the regulations for briquettes. However, for the briquettes with 30-70 wt.\% SCG, the $\mathrm{SO}_{2}$ concentration gradually decreased to $5.8,4.7,2.2$, and $1.4 \mathrm{ppm}(13 \%$ $\mathrm{O}_{2}$ ), respectively, as the sulfur content decreased, despite the volatile substance content exceeding the 7.0 wt.\% limit.

\section{Conclusions}

This study evaluated the potential for replacing anthracite briquettes with briquettes made using SCG, a biomass raw material. Considering the fuel quality and shape retention of the briquettes, the optimal SCG briquette was one with an SCG content of 20 wt.\%, a BA content of 71 wt.\%, a KC content of 9 wt.\%, and a 15 wt.\% moisture content adjusted by adding a moisture additive with a 20:1 water $/ \mathrm{Ca}(\mathrm{OH})_{2}$ mixing ratio. This briquette exhibited a durability of $86 \%$ before combustion and $99.46 \%$ after combustion and an LHV of $15.8 \mathrm{MJ} / \mathrm{k}$. Analysis of the physicochemical properties of the SCG briquette and combustion tests using a briquette boiler confirmed the potential of this SCG briquette as an alternative fuel to anthracite briquettes.

Compared to anthracite briquettes, the SCG briquette has lower durability. However, the durability is sufficient for use in existing briquette boilers. In addition, an increased SCG content resulted in greater heat generation and a lower combustion time. Anthracite briquettes exhibit higher $\mathrm{CO}$ and $\mathrm{CO}_{2}$ emissions due to incomplete combustion. Moreover, the combustion rate of SCG briquettes increased as the SCG content increased, reducing emissions. $\mathrm{NO}_{2}$ and $\mathrm{SO}_{2}$ emissions related to $\mathrm{BA}$ and $\mathrm{KC}$ contents were higher in briquettes with 20\% SCG than in anthracite briquettes; however, emissions were still significantly lower than the emission threshold. In conclusion, SCG briquettes have substantial economic value with a small environmental footprint, making them a promising alternative to anthracite briquette fuels.

\section{Acknowledgments}

This research was supported by the Ministry of Trade, Industry \& Energy (MOTIE), Korea Institute for Advancement of Technology (KIAT) through the Community Business Activation Program (Development of Eco Innovation System and Product using coffee waste, P0008723).

\section{Author Contributions}

Y.S.K. (Ph.D. student) conducted conceptualization, methodology, formal analysis, investigation, data curation, and writing - original draft. T.S.P. (Assistant Professor) conducted investigation, methodology, validation, and writing - review and editing. D.H.H. (Research Professor) conducted conceptualization, methodology, resources, visualization, supervision, funding acquisition, and writing - review and editing. All authors have read and agreed to the published version of the manuscript.

\section{References}

1. Li Q, Li X, Jiang J, et al. Semi-coke briquettes: towards reducing emissions of primary PM 2.5, particulate carbon and carbon monoxide from household coal combustion in China. Sci. Rep. 2016;6:1-10.

2. Zhang Y, Schauer J, Zhang Y, et al. Characteristics of particulate carbon emissions from real-world Chinese coal combustion. Environ. Sci. Technol. 2008;42:5068-5073.

3. Wang SX, Zhao B, Cai SY, et al. Emission trends and mitigation options for air pollutants in East Asia. Atmos. Chem. Phys. 2014;14:6571-6603

4. Zhao B, Wang SX, Liu H, et al. NOx emissions in China: historical trends and future perspectives. Atmos. Chem. Phys. 2013;13: 9869-9897.

5. Gómez-De La Cruz FJ, Cruz-Peragón F, Casanova-Peláez PJ, Palomar-Carnicero JM. A vital stage in the large-scale production of biofuels from spent coffee grounds: the drying kinetics. Fuel. Process. Technol. 2015;130:188-196.

6. Mata TM, Martins AA, Caetano NS. Bio-refinery approach for spent coffee grounds valorization. Bioresour. Technol. 2018;247: 1077-1084.

7. Shiferaw Y, Tedla A, Mellese C, et al. Conversion of coffee residue waste and Eucalyptus globulus leaf extract into an alter- 
native solid fuel. Energy Sources, Part A: Recovery Util. Environ. Effects. 2018;40:780-786.

8. Campos-Vega R, Loarca-Pina G, Vergara-Castaneda HA, Oomah BD. Spent coffee grounds: A review on current re-search and future prospects. Trends in Food Sci. Technol. 2015;45:24-36.

9. International Coffee Organization. Monthly Coffee Market Report-February 2021. [Internet]. C2021. [cited 30 March]. Available from: http://www.ico.org/Market-Report-20-21-e.asp

10. Santos C, Fonseca J, Aires A, Coutinho J, Trindade H. Effect of different rates of spent coffee grounds (SCG) on composting process, gaseous emissions and quality of end-product. Waste Management. 2017;59:37-47.

11. Girotto F, Pivato A, Cossu R, Nkeng GE, Lavagnolo MC. The broad spectrum of possibilities for spent coffee grounds valorisation. J. Mater. Cycles Waste Manag. 2018;20(1), 695-701.

12. García-García D, Carbonell A, Samper MD, García-Sanoguera D, Balart R. Green composites based on polypropylene matrix and hydrophobized spend coffee ground (SCG) powder. Composites part B: Eng. 2015;78:256-265.

13. Chen J, Liu J, He Y, et al. Investigation of co-combustion characteristics of sewage sludge and coffee grounds mixtures using thermogravimetric analysis coupled to artificial neural networks modeling. Bioresour. Technol. 2017;225:234-245.

13. Kourmentza C, Economou CN, Tsafrakidou P, Kornaros M. Spent coffee grounds make much more than waste: exploring recent advances and future exploitation strategies for the valorization of an emerging food waste stream. J. Clean. Prod. 2018;172:980-992.

15. Muazu RI, Stegemann JA. Biosolids and microalgae as alternative binders for biomass fuel briquetting. Fuel 2017;194: 339-347.

16. Shankar T, Christopher T, Wright JRH, Kenney KL. A review of biomass densification systems to develop uniform feedstock commodities for bioenergy application. Biofuels Bioprod. Biorefin. 2011;5:683-707.

17. Kaliyan N, Vance-Morey R. Factors affecting strength and durability of densified biomass products. Biomass Bioenergy. 2009;33:337-359.

18. Espuelas S, Marcelino S, Echeverría AM, del Castillo JM, Seco A. Low energy spent coffee grounds briquetting with organic binders for biomass fuel manufacturing. Fuel 2020;278:118310.

19. Emadi B, Iroba KL, Tabil LG. Effect of polymer plastic binder on mechanical, storage and combustion characteristics of torrefied and pelletized herbaceous biomass. Appl. Energy. 2017;198: 312-319.

20. Chen WH, Cheng WY, Lu KM, Huang YP. An evaluation on improvement of pulverized biomass property for solid fuel through torrefaction. Appl. Energy. 2011;88:3636-3644.

21. ASTM D7582-15, Standard Test Methods for Proximate Analysis of Coal and Coke by Macro Thermogravimetric Analysis, ASTM International, West Conshohocken, PA, 2015, www.astm.org

22. Ministry of Environment Examination No. 2014-135 (Methods for testing and analyzing quality of solid fuel products)

23. Zyrkowski M, Neto RC, Santos LF, Witkowski K. Characterization of fly ash cenospheres from coal-fired power plant unit. Fuel 2016;174:49-53.

24. Ahmaruzzaman M. A review on the utilization of fly ash. Prog.
Energy. Combust. Sci. 2010;36:327-363.

25. Chindaprasirt P, Jaturapitakkul C, Chalee W, Rattanasak U. Comparative study on the characteristics of fly ash and bottom ash geopolymers. Waste. Manag. 2009;29:539-543.

26. Cheriaf M, Rocha JC, Pera J. Pozzolanic properties of pulverized coal combustion bottom ash. Cem. Concr. Res. 1999;29:1387-1391.

27. Sathonsaowaphak A, Chindaprasirt P, Pimraksa K. Workability and strength of lignite bottom ash geopolymer mortar. J. Hazard Mater. 2009;168:44-50.

28. Chindaprasirt P, Jaturapitakkul C, Chalee W, Rattanasak U. Comparative study on the characteristics of fly ash and bottom ash geopolymers. Waste Manag. 2009;29:539-543.

29. Panda AK, Mishra BG, Mishra DK, Singh RK. Effect of sulphuric acid treatment on the physico-chemical characteristics of kaolin clay. Colloids. Surf. A Physicochem. Eng. Asp. 2010;363:98-104.

30. Belver C, Bañares-Muñoz MA, Vicente MA. Chemical activation of a kaolinite under acid and alkaline conditions. Chem. Mater. 2002;14:2033-2043.

31. Ouyang C, Wang S, Zhang Y, Zhang Y. Thermo-rheological properties and storage stability of SEBS/kaolinite clay compound modified asphalts. Eur. Polym. J. 2006;42:446-457.

32. Potip S, Wongwuttanasatian T. Combustion characteristics of spent coffee ground mixed with crude glycerol briquette fuel. Combust. Sci. Technol. 2018;190:2030-2043.

33. Allesina G, Pedrazzi S, Allegretti F, Tartarini P. Spent coffee grounds as heat source for coffee roasting plants: Experi-mental validation and case study. Appl. Therm. Eng. 2017;126:730-736.

34. Emadi B, Iroba K.L, Tabil LG. Effect of polymer plastic binder on mechanical, storage and combustion characteristics of torrefied and pelletized herbaceous biomass. Appl. Energy. 2017;198:312-319.

35. Kang SB, Oh HY, Kim JJ, Choi KS. Characteristics of spent coffee ground as a fuel and combustion test in a small boiler (6.5 kW). Renew. Energy. 2017;113:1208-1214.

36. Law HC, Gan LM, Gan HL. Experimental study on the mechanical properties of biomass briquettes from different agricultural residues combination. MATEC Web Conf. 2018;225:04026.

37. Seco A, Espuelas S, Marcelino S, Echeverría AM, Prieto E. Characterization of biomass briquettes from spent coffee grounds and xanthan gum using low pressure and temperature. Bioenergy Res. 2019;13:1-9.

38. Chai L, Saffron CM. Comparing pelletization and torrefaction depots: Optimization of depot capacity and biomass mois-ture to determine the minimum production cost. Appl. Energy. 2016;163:387-395.

39. Warajanont S, Soponpongpipat N. Effect of particle size and moisture content on cassava root pellet fuel's qualities follow the acceptance of pellet fuel standard. Inter. J. Sustain. Green Ener. 2013;3:7-17.

40. Rajaseenivasan T, Srinivasan V, Syed Mohamed Qadir G, Srithar $\mathrm{K}$. An investigation on the performance of sawdust briquette blending with neem powder. Alexandria Eng. J. 2016;55: 2833-2838.

41. Werther J, Saenger M, Hartge EU, Ogada T, Siagi Z. Combustion of agricultural residues. Prog. Energy. Combust. Sci. 2000;26: 1-27.

42. Chen WH, Lu KM, Tsai CM. An experimental analysis on prop- 
erty and structure variations of agricultural wastes un-dergoing torrefaction. Appl. Energy. 2012;100:318-325.

43. Tsai WT, Liu SC. Effect of temperature on thermochemical property and true density of torrefied coffee residue. J. Anal. Appl. Pyrolysis. 2013;102:47-52.

44. Cheriaf M, Rocha JC, Pera J. Pozzolanic properties of pulverized coal combustion bottom ash. Cem. Concr. Res. 1999;29: 1387-1391.

45. Sathonsaowaphak A, Chindaprasirt P, Pimraksa K. Workability and strength of lignite bottom ash geopolymer mortar. J. Hazard. Mater. 2009;168:44-50.

46. Chindaprasirt P, Jaturapitakkul C, Chalee W, Rattanasak U. Comparative study on the characteristics of fly ash and bottom ash geopolymers. Waste. Manag. 2009;29:539-543.

47. Kaliyan N, Morey RV. Natural binders and solid bridge type binding mechanisms in briquettes and pellets made from corn stover and switchgrass. Bioresour. Technol. 2010;101:1082-1090.

48. Koppejan J, Van-Loo S. The Handbook of Biomass Combustion and Co-firing. Routledge. London: Routledge; 2012. p.38-77.

49. Yin CY. Prediction of higher heating values of biomass from proximate and ultimate analyses. Fuel 2011;90:1128-1132.

50. Kim J, Kim H, Lim D, Lee J, Shin M. Analysis and evaluation of the combustion response characteristics for the Bottom ash/Fly ash in a thermal power plant. The Academy of Mechanical Engineering. 2015:3943-3946.
51. Enforcement Rules for the Conservation of Atmospheric Environment Act. Enforcement of the Environmental Protection Decree, No. 866. 2020.

52. Obernberger I, Brunner T, Bärnthaler G. Chemical properties of solid biofuels - significance and impact. Biomass. Bioenergy. 2006;30:973-982.

53. Pusz S, Szeluga U, Nagel B, Czajkowska S, Galina H, Strzezik J. The influence of structural order of anthracite fillers on the curing behavior, morphology, and dynamic mechanical thermal properties of epoxy composites. Polymer Composites. 2015; 36(2):336-347.

54. Fournel S, Palacios JH, Morissette R, Villeneuve J, Godbout S, Heitz M, Savoie P. Influence of biomass properties on technical and environmental performance of a multi-fuel boiler during on-farm combustion of energy crops. Appl. Energy. 2015;141 247-259.

55. Research and Management of the Emission Sources of Air Pollutants. Konetic Report. Korea Environment Industry and Technology Institute, 2020. Available from: https:/www.konetic. or.kr/main/REPORT/REPORT_VIEW.asp?PARENT_NUM=347.

56. Air Pollution. Ministry of Environment, 2020. Available from: https://www.me.go.kr/mamo/web/index.do?menuId=587.

57. Nussbaumer T. Combustion and co-combustion of biomass: fundamentals, technologies, and primary measures for emission reduction. Energy. Fuels. 2003;17:1510-1521. 